\title{
The sagittal re-alignment brace in the treatment of chronic low back pain in patients with lumbar kyphosis HR Weiss*, M Werkmann and S Bohr
}

\author{
Address: Orthopedic Rehabilitation Services Alzeyer Str. 23 D-55457 Gensingen, Germany \\ Email: HR Weiss* - hr.weiss@koob-scolitech.com \\ * Corresponding author
}

from 6th International Conference on Conservative Management of Spinal Deformities Lyon, France. 21-23 May 2009

Published: I4 December 2009

Scoliosis 2009, 4(Suppl 2):O62 doi:I0.I I86/I748-7|6|-4-S2-O62

This abstract is available from: http://www.scoliosisjournal.com/content/4/S2/O62

(C) 2009 Weiss et al; licensee BioMed Central Ltd.

\section{Background}

For adult scoliosis patients with chronic low back pain, bracing is initially indicated before spinal surgery is considered. Until recently, the effect bracing treatment has on middle to long-term pain reduction has not been reported. Promising results have been documented in the short-term for the application of a sagittal re-alignment brace in patients with spinal deformities and suffering from pain; however mid-term or long-term results are not yet available.

\section{Objective}

The objective of this study is to investigate the mid-term effects that sagittal realignment bracing treatment has on pain control.

\section{Materials and methods}

65 patients (56 females and 9 males) with chronic low back pain (> 24 months) and the diagnosis of scoliosis or kyphosis were treated with a sagittal realignment brace (physio-logic brace ${ }^{\mathrm{TM}}$ ) between January 2006 and July 2007. All patients had a lumbar kyphosis. The indication for this kind of brace treatment was derived from a positive sagittal re-alignment test (SRT) and the restriction of no successful conservative treatment during the last 24 months (Figure 1).

The aim of this intervention was to avoid surgery for chronic low back pain.

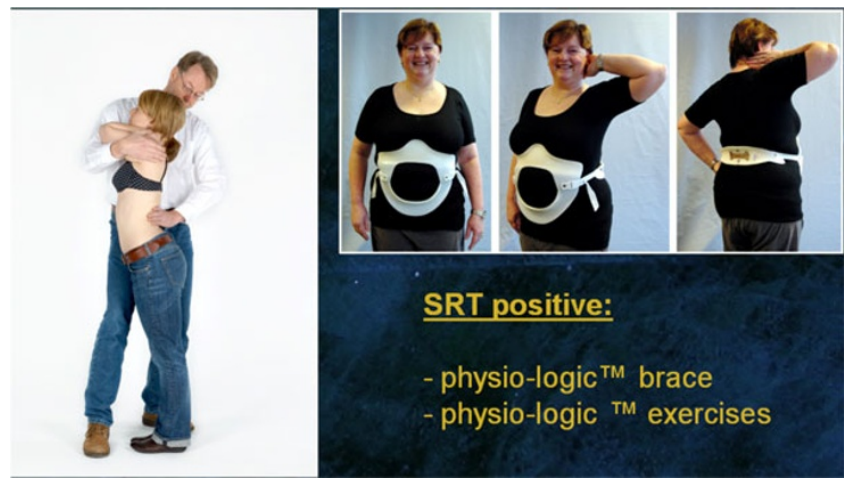

Figure I

\section{Results}

The average pain intensity on the Roland and Morris VRS (5 steps) before treatment was $3.3(\mathrm{t} 1)$, at the time of brace adjustment $2.7(\mathrm{t} 2)$, and after an average observation time of 18 months $2.0(\mathrm{t} 3)$. The differences were highly significant in the Wilcoxon test.

\section{Discussion}

Mid-term measurements showed that a significant pain reduction is possible in chronic postural low back pain using a sagittal realignment brace inducing lumbar re-lordosation. 


\section{Conclusion}

The brace action of the sagittal re-alignment brace leads to promising mid-term improvements in patients with chronic low back pain and spinal deformities. Contrary to unspecific orthoses, which after a short period are no longer worn, the sagittal re-alignment brace (physiologic $^{\text {TM }}$ brace) leads to an effective reduction of pain intensity in the mid-term, even in patients who have stopped brace treatment after the initial 6 months of treatment. Therefore, in conservative treatment of chronic low back pain, specific approaches such as the sagittal re-alignment brace should be applied first, before a risky operation is performed.

Publish with Bio Med Central and every scientist can read your work free of charge

"BioMed Central will be the most significant development for disseminating the results of biomedical research in our lifetime. " Sir Paul Nurse, Cancer Research UK

Your research papers will be:

- available free of charge to the entire biomedical community

- peer reviewed and published immediately upon acceptance

- cited in PubMed and archived on PubMed Central

- yours - you keep the copyright

Submit your manuscript here:

http://www.biomedcentral.com/info/publishing_adv.asp 